\title{
The determination of model dimension for an embankment to study soil atmosphere interaction with Finite Element Method
}

\author{
Ni An ${ }^{1, \text { a }}$, Sahar Hemmati ${ }^{2}$, Yu-jun Cui ${ }^{1}$ and Anh-minh Tang ${ }^{1}$ \\ ${ }^{1}$ Laboratoire Navier/CERMES, Ecole des Ponts ParisTech, 77455 Marne la Vallée, France \\ ${ }^{2}$ IFSTTAR - French institute of science and technology for transport, development and networks, 77447 Marne la Vallée, France
}

\begin{abstract}
In order to study the interaction between soil and atmosphere, Héricourt experimental embankment was instrumented with different equipments for collecting the meteorological data, runoff, soil temperature and volumetric water content, etc. The corresponding water flux and heat flux boundary conditions of the Hydro-thermal coupled model of unsaturated soil can be calculated based on the energy and mass balance. However, in Finite Element Method, a suitable model dimension of experimental embankment needs to be set in advance, which will diminish the effect of bottom and lateral boundaries. Therefore, in this paper, four different dimension models are calculated respectively and compared in two cases with different boundary conditions. For Case 1, top water flux boundary condition is set as infiltration and evaporation happening on the soil surface alternately. In Case 2, top heat flux boundary condition is assumed based on daily solar radiation value. Comparing the results of four model dimensions, temperature and volumetric water content distributions in four dimensions lead nearly consistent results. Therefore, with consideration of computational time and accuracy, dimension 2 or 3 is suggested for Hydro-thermal study of Héricourt embankment case.
\end{abstract}

\section{Introduction}

For numerical calculation, it is important to set suitable dimension to describe the real situations of problem. In literature, a typical dimension value of embankment model for mechanical numerical calculation has been suggested by Azizi [1]. Rujikiatkamjorn et al. [2] proposed a 3D model based on Finite Difference Method in Hexagonal Wire Mesh by FLAC 3D, which was applied to simulate the vertical settlement, excess pore pressures and lateral displacements of an embankment on soft Bangkok clay. With an experienced dimension, Yue [3] simulated the thermal regime of embankment and berm in permafrost based on 2D embankment model with finite element method. Kalliainen et al. [4] studied the effect of embankment dimensions on the mechanical behavior of railway track, showing that the embankment dimensions had a slight effect on the accumulated permanent deformations of the embankment on a very stiff subgrade. However, on more flexible subgrade, the rate of accumulated permanent deformation is remarkable and the effect of embankment dimension on accumulated permanent deformation of the embankment is also clearly visible. In the study of mechanical behavior of

\footnotetext{
corresponding author: ann@cermes.enpc.fr
} 
embankment, it is subgrade stiffness that has a remarkable effect on its deformation behaviour, not the embankment dimension.

With the experiences in literature, in most cases, model dimension was set for hydraulic or mechanical study, which asks for more attention on the variation of soil water content, strain and stress over time. However, for Hydro-thermal coupled model of unsaturated soil, no related suggestion of model dimension was proposed for numerical calculation. In this paper, in order to get an ideal model dimension for field Héricourt embankment, four different dimensions are compared. By adding water flux and heat flux boundary conditions respectively, the soil volumetric water content and temperature variations are calculated by Finite Element Method. Based on the comparison results, with considering computational accuracy and time consumed, the suitable dimension value is suggested to be applied in further study about the interaction between atmosphere and unsaturated soil.

\section{Material and method}

\subsection{Soil parameters}

Studied Héricourt embankment was constructed by lime/cement treated silt. Relevant experimental work was conducted in order to get its parameters.

The thermal conductivity of treated silt is set to be linear to volumetric water content as proposed by De Vries [5]. Fig. 1 presents the variation of thermal conductivity as function of volumetric water content. Based on the test results, the fitting curve is expressed as,

$$
\lambda=2.1818 \theta+0.808
$$

where $\lambda$ is thermal conductivity $(\mathrm{W} / \mathrm{mK}), \theta$ is volumetric water content.

With the testing data shown in Fig. 2, the fitting water retention curve based on Van Genuchten model could be drawn. In the same model, accompanied with the saturated hydraulic conductivity measured, its unsaturated hydraulic conductivity curve is drawn in Fig. 3. Accordingly, soil water retention curve and hydraulic conductivity are written as equation (2) and (3) respectively,

$$
\begin{aligned}
& S_{e}=\frac{\theta-\theta_{r}}{\theta_{s}-\theta_{r}}=\left[\frac{1}{1+(\partial \varphi)^{n}}\right]^{m} \\
& K=K_{s} \mathrm{~S}^{0.5}\left[1-\left(1-\mathrm{S}_{\mathrm{e}}{ }^{1 / m_{1}}\right)^{m_{1}}\right]^{2}
\end{aligned}
$$

where saturated volumetric water content $\theta_{\mathrm{s}}=0.4$, residual volumetric water content $\theta_{\mathrm{r}}=0.004$, parameter $\alpha$ $=0.003 \mathrm{kPa}^{-1}, m=0.18, n=1.8, m_{1}=0.5$, saturated hydraulic conductivity $K_{\mathrm{s}}=10^{-9} \mathrm{~m} / \mathrm{s}$.

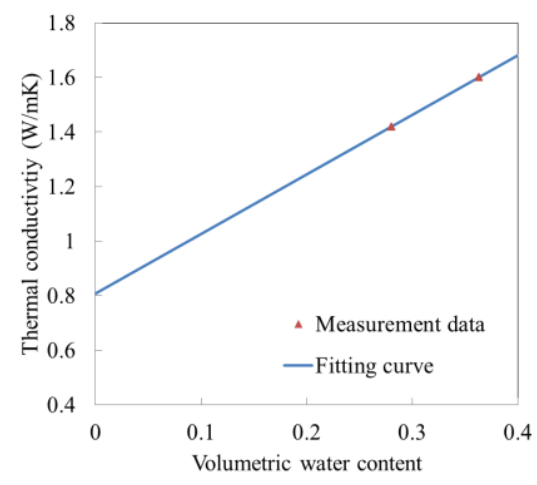

Figure 1. Thermal conductivity of treated silt

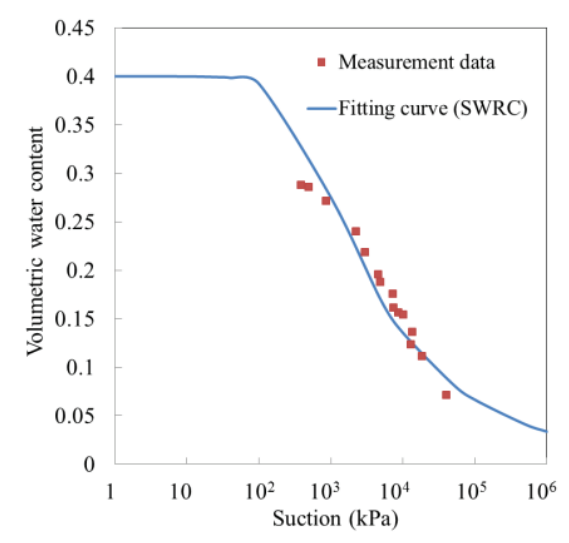

Figure 2. Soil retention curve of treated silt

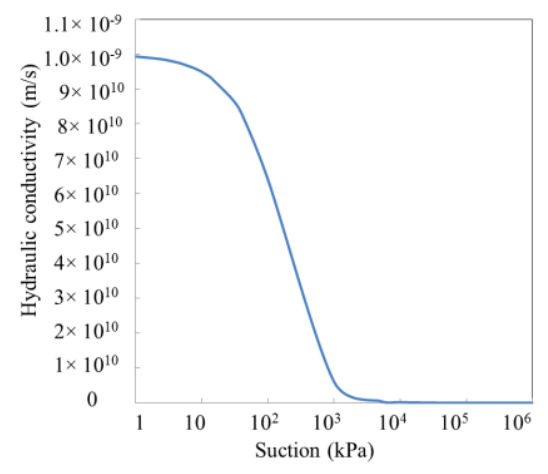

Figure 3. Hydraulic conductivity curve of treated silt 


\subsection{Model dimension}

Normally, because of symmetry, further simplification is made by modeling only half of the whole embankment. To avoid the spurious influence from boundary conditions, four different dimensions of the finite element mesh are tested. Their details are listed in Table 1, Fig. 4 and Fig. 5. Dimension 4 is set based on the typical dimension of embankment model for mechanical numerical calculation suggested by Azizi [1]. Three other dimensions are set in order to be compared for studying the effect of boundary conditions. Dimension 1 is the original embankment size with part of basement. Dimension 2 and 3 are extended in different sizes respectively.

In addition, section $\mathrm{A}$ and $\mathrm{B}$ as shown in Fig. 4 are chosen to record the influence of different dimensions on numerical results. Six points with different depths from soil surface in section $\mathrm{A}$ and section $\mathrm{B}$ are selected (P1-0.00 m, P2-0.25 m, P3-0.50 m, P4-0.75 m, P5-1.00 m, P6-1.50 m). The groundwater table is assumed at the depth of $5 \mathrm{~m}$ from the ground as shown in Fig. 4. The bottom boundary condition is set as with constant $10^{\circ} \mathrm{C}$ temperature. No water and heat transfer happen to the left and right boundaries.

Two Cases with different top boundary conditions are conducted for dimension analysis. Case 1 is calculated with just hydraulic boundary conditions (heat flux boundary is zero) and Case 2 is conducted with only thermal boundary conditions (hydraulic flux boundary is zero). The details are explained in the next chapter. In terms of the initial condition, the uniform initial temperature of treated silt is assumed as $\mathrm{T}_{0}=10{ }^{\circ} \mathrm{C}$. Besides, the soil above groundwater table is in unsaturated state whose suction is expressed as function $\mathrm{U}_{0}=-\mathrm{y}$ (Fig. 4), where y is soil depth from top surface of embankment.

Table 1. The details of four dimensions

\begin{tabular}{|l|l|l|}
\hline Item & $\mathrm{L}_{\mathrm{e}}$ & $\mathrm{H}_{\mathrm{e}}$ \\
\hline Dimension 1 & 0 & $5 \mathrm{~m}$ \\
\hline Dimension 2 & $0.5 \mathrm{~L}$ & $5 \mathrm{~m}$ \\
\hline Dimension 3 & $1.5 \mathrm{~L}$ & $3 \mathrm{H}$ \\
\hline Dimension 4 & $>3 \mathrm{~L}$ & $\approx 5 \mathrm{H}$ \\
\hline
\end{tabular}

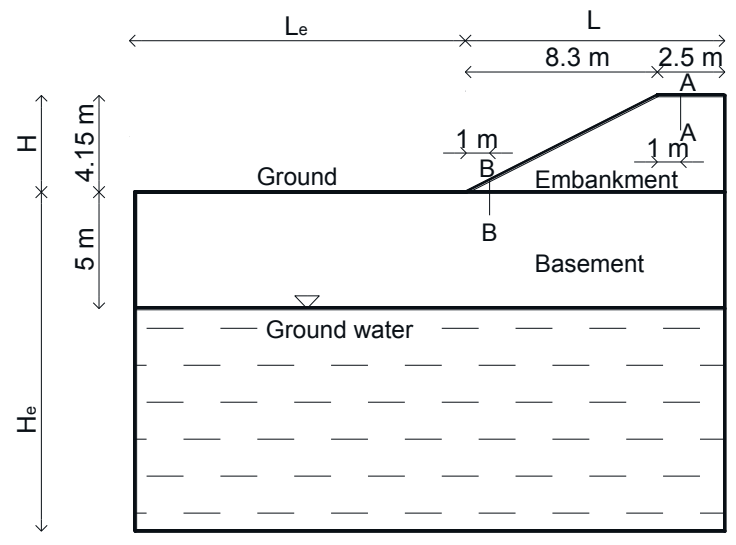

Figure 4. Embankment sketch and two section positions

\section{Results and analysis}

\subsection{Case 1}

The top boundaries of this embankment consist of top, slope surface of embankment and ground surface. For Case 1, it is supposed that evaporation $\left(10^{-7} \mathrm{~m} / \mathrm{s}\right)$ and infiltration $\left(5 \times 10^{-8} \mathrm{~m} / \mathrm{s}\right)$ happen alternately during six days. Water flux top boundary condition as shown in Fig. 5 and zero heat flux top boundary condition are applied at the same time.

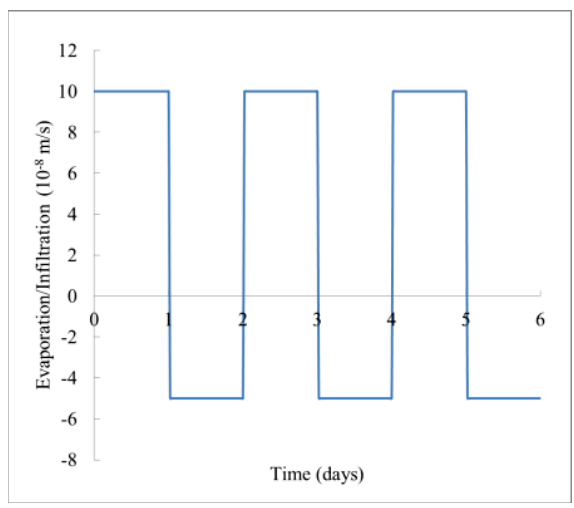

Figure 5. Water flux top boundary condition

Based on the Hydro-thermal coupled model of treated silt, only alternate infiltration and evaporation in six days are added as top boundary condition. With the volumetric water content variations of six points in section $\mathrm{A}$ and $\mathrm{B}$ recorded continuously. It can be seen that the values in six points are nearly consistent in four different dimensions (Fig. 6 et Fig. 7, 1-P1 represents point 1 in dimension 1, 2-P2 represents point 2 in dimension 2, etc.). However, the 
temperature of soil keeps as the initial value when no heat flux exchange happens.

The results of section A in Fig. 6 show that volumetric water content of each point changes regularly as the water flux changes on the top boundary. When evaporation happens, volumetric water content of surface point $\mathrm{P} 1$ decreases to about 0.323 at the first day, then goes back to nearly saturated situation at the second day, continuously drops to $0.312,0.301$ in the third and fifth day with rebounding to $0.387,0.381$ in the fourth and last day respectively. For point P2, it shows the similar going up and down circulation as the surface point P1. While for point P3, P4, P5 and P6, they show the decrease tendency continuously. Point P3, P4, P5 and P6 are so far from top surface that no apparent rebound phenomenon exists. It can be inferred that water flux boundary effects will not be reflected in soil layers whose depth is larger than $1 \mathrm{~m}$ in this embankment. Furthermore, compared with point P1, it is observed that obvious time lag to reach the peak volumetric water content exists for point P2 because of its deeper position to the surface than point P1. Generally, these six lines show that the effect of top surface water flux boundary condition on soil volumetric water content becomes weaker in deeper positions.

Compared with other three dimensions, dimension 1 doesn't consider the effect of left ground to embankment slope toe. In Fig. 7, for section B that is located $1 \mathrm{~m}$ away to the slope toe of embankment, the results of dimension 1 show a little difference with other three dimensions. The minimum values for surface point $\mathrm{P} 1$ reach 0.329, 0.319, 0.309 respectively in the first, third, fifth day, which all are a little larger than those values in section A. It is caused by the gravity effect of liquid flow. Thus higher volumetric water content exists on the slope surface than the top surface of embankment.

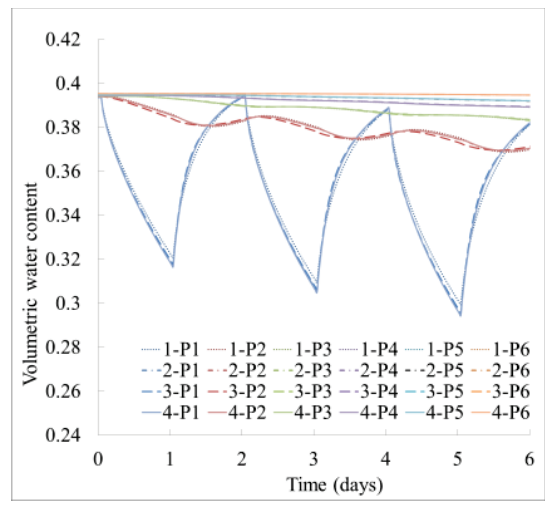

Figure 6. Volumetric water content change of six points in section $\mathrm{A}$ in four dimensions

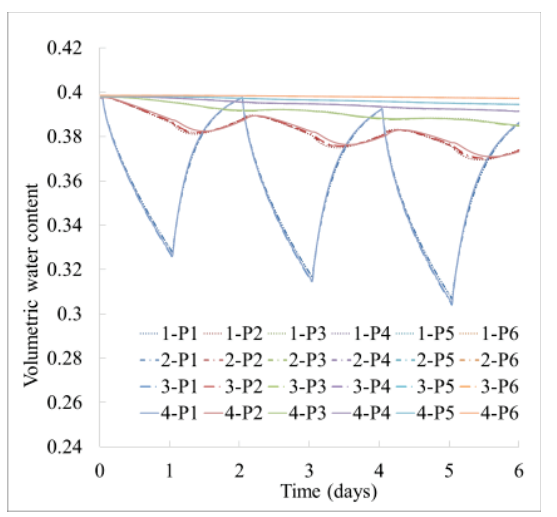

Figure 7. Volumetric water content change of six points in section $\mathrm{B}$ in four dimensions

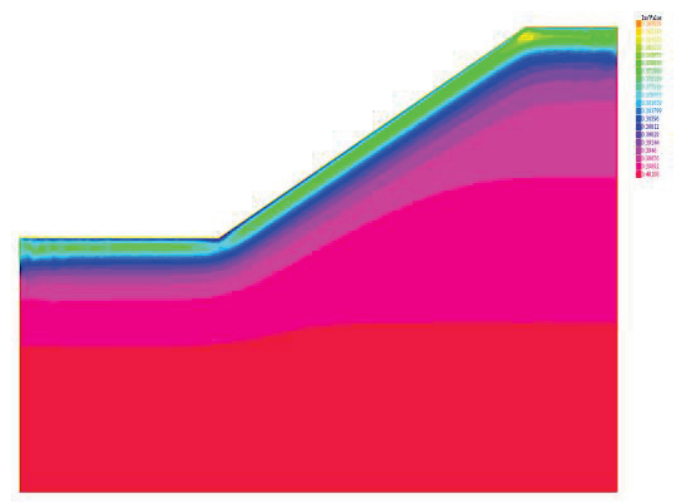

Figure 8. Volumetric water content distribution of dimension 2

As shown in Fig. 8, the contour line of volumetric water content of dimension 2 is parallel to the surface line of embankment. The influencing region by the top boundary condition of water flux is in the first meter of depth for this embankment. In fact, the distribution of volumetric water content in the region near surface of dimension 1, 3 and 4 are similar to dimension 2. What needs to be mentioned is that, because of the gravity effect, the region of left ground near slope toe cannot be 
neglected in numerical calculation. It will lead a more reasonable result with considering slope toe in our model.

\subsection{Case 2}

In the second case, based on the real solar radiation, heat boundary condition is assumed as the top boundary condition, positive $45 \mathrm{~W} / \mathrm{m}^{2} \mathrm{~s}$ for 6 hours in day time and negative $15 \mathrm{~W} / \mathrm{m}^{2}$ s for 18 hours during night time (Fig. 9a et Fig. 9b).

The six points of two sections are nearly consistent in four different dimensions (Fig. 10 et Fig. 11). As shown in Fig. 10, in the first nine hours of nighttime when soil heat is negative as $15 \mathrm{~W} / \mathrm{m}^{2} \mathrm{~s}$, surface point $\mathrm{P} 1$ decreases quickly to $8.69{ }^{\circ} \mathrm{C}$ and goes up to $12.65{ }^{\circ} \mathrm{C}$ in the daytime when receiving positive soil heat $45 \mathrm{~W} / \mathrm{m}^{2} \mathrm{~s}$. During six days, it keeps nearly the same minimum and maximum temperature in each day. The similar situation exists in point $\mathrm{P} 2$, which is in temperature variation range 9.80 10.20 ${ }^{\circ} \mathrm{C}$. Obvious time delay of 2.4 to 4.8 hours could be observed for points $\mathrm{P} 2$ compared with point P1 because of deeper position of point P2. Point P3, P4, P5 and P6 keep nearly constant temperature as the initial value, which means that they are located out of the influencing region of surface heat flux. This influencing depth is closely related to the thermal conductivity of treated soil.
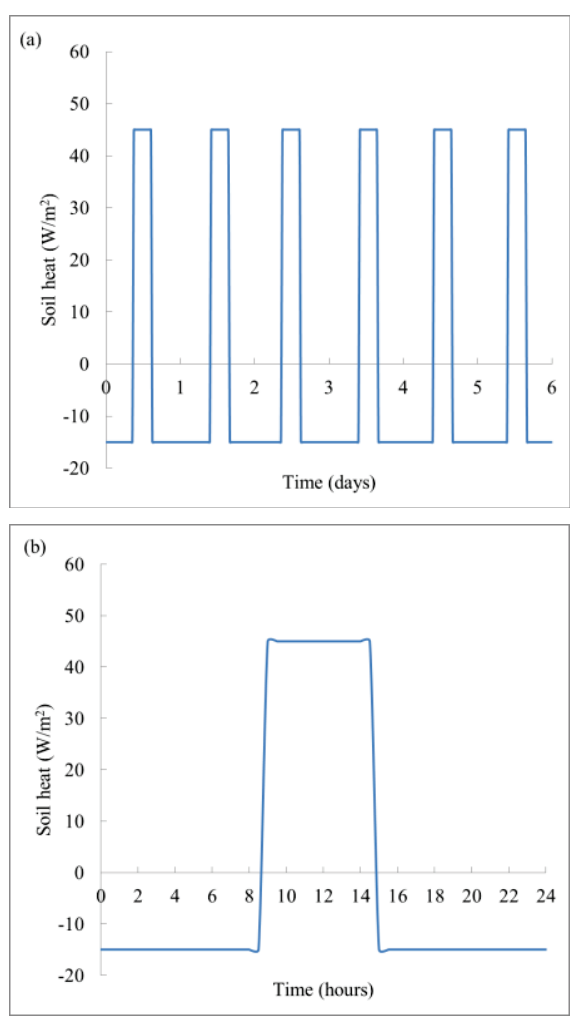

Figure 9.

(a) Heat flux top boundary condition in six days

(b) Details of heat flux variations in 24 hours

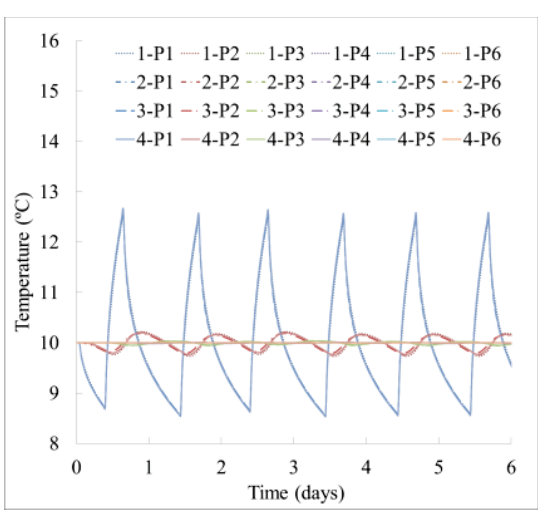

Figure 10. Temperature change of six points in section $\mathrm{A}$ in four dimensions 


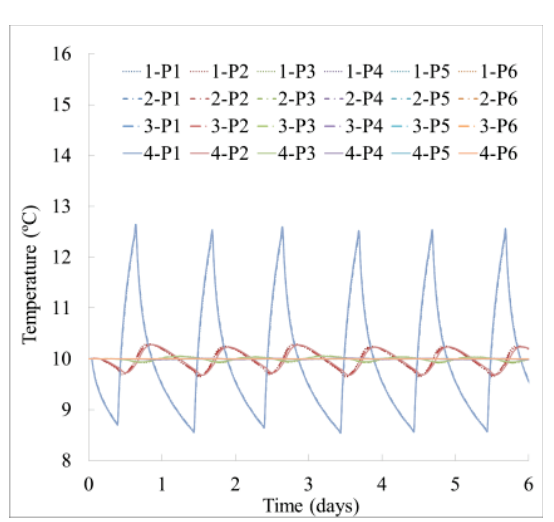

Figure 11. Temperature change of six points in section B in four dimensions

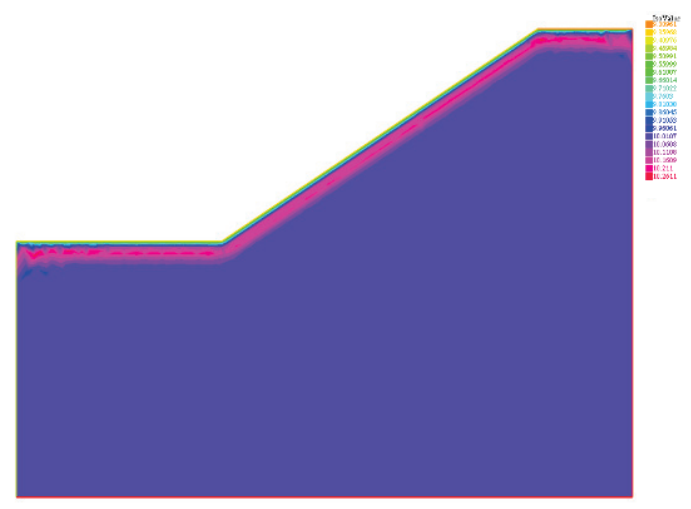

Figure 12. Temperature distribution of dimension 2

In Fig. 11, for section B, it shows nearly all the same results in values and variation patterns as section $\mathrm{A}$. The other three dimensions have the same temperature distribution as dimension 2 shown in Fig. 12. The contour line of temperature distribution is parallel to the surface line. The influencing region of soil surface heat flux is in about $0.5 \mathrm{~m}$ of depth. In addition, the consideration of left ground effect on slope toe doesn't change the general temperature distribution of embankment.

In terms of Case 2, what is different with Case 1 is that the temperature gradient changes volumetric water content distribution. However, this effect could be neglected because of the small differences of values they caused. The volumetric water content is influenced by gravity initially and varies slightly, then keep almost stable in the six days when water flux boundary condition is set as zero.

In this study, it is preferred to focus on Hydro-thermal behavior of unsaturated soil. Dimension 4 could be regarded as reliable because that its size is based on mechanical analysis, which is highly sensitive to dimension selection. However, apart from left ground effect on slope toe the volumetric water content results of section $\mathrm{B}$ in dimension 1, the results of other three dimensions show that different dimensions will not lead large differences on volumetric water content and temperature distribution in this field embankment. Therefore, the effect of model dimension is not significant for Hydro-thermal coupled unsaturated soil model.

The soil surface temperature and volumetric water content studied are controlled by the interaction between atmosphere and unsaturated soil. The contour lines of volumetric water content and temperature distribution are always parallel to the surface line. Consequently, more attention needs to be paid for the top boundary conditions.

\section{Conclusions}

In order to study the interaction between atmosphere and embankment, the Hydro-thermal coupled unsaturated soil model is used to calculate the reaction of soil under instantaneous boundary conditions. With abundant meteorological data, the corresponding water flux and heat flux boundary condition could be obtained conveniently relying on the energy and mass balance. With Finite Element Method, a suitable dimension of this embankment needs to be set in advance, which takes the possible influencing region from atmosphere into consideration in the numerical calculation.

In sum, four different dimension models are calculated respectively in two Cases. The first one is applied with water flux boundary condition, considering boundary heat flux as zero. Another one is applied with heat flux boundary condition based on the daily solar radiation values with no water flux exchange. Compared three dimensions with the results of the reliable model dimension (dimension 4), the temperature and volumetric water content values and variation patterns in these dimensions are nearly consistent. The contour lines of volumetric water content and temperature distribution are parallel to the surface line. It can be concluded that the effect of model dimension to field embankment is not significant for Hydro-thermal coupled unsaturated soil research. In dimension 1, the effect of left ground on embankment slope toe is not fully considered, which is not advised based on the analysis in this study. Therefore, 
with consideration of less demanding of computational time and memory, dimension 2 or 3 are suggested to be adopted in the further study.

\section{References}

1. F. Azizi, Applied Analyses in Geotechnics (E \& FN Spon Press, 2000)

2. C. Rujikiatkamjorn, B.Indraratna, D. T.Bergado, 3D numerical modelling of hexagonal wire mesh reinforced embankment on soft Bangkok silt, Geo Congress, 2263-2272 ( 2012)

3. Z.R. Yue, Thermal regime simulation of embankment and berm in permafrost, Geomechanics and Geoengineering, 3 (2), 97-105 ( 2008)

4. A. Kalliainen, P. Kolisoja, A. Nurmikolu, Modeling of the effect of embankment dimensions on the mechanical behavior of railway track, Joint Rail Conference 1, 389-398 (2010)

5. D. A. DeVries, Thermal Properties of Soils, Physics of Plant Environment (North-Holland Publishing Co., Amsterdam, 210-235, 1963) 